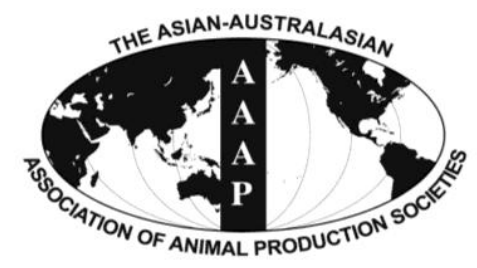

Asian Australas. J. Anim. Sci.

Vol. 26, No. 10 : 1388-1398 October 2013

http://dx.doi.org/10.5713/ajas.2013.13109

www.ajas.info

pISSN 1011-2367 elSSN 1976-5517

\title{
Effect of Carcass Traits on Carcass Prices of Holstein Steers in Korea
}

\author{
M. Alam, K. H. Cho, S. S. Lee, Y. H. Choy, H. S. Kim ${ }^{1}$, C. I. Cho, and T. J. Choi* \\ National Institute of Animal Science, RDA, Cheonan Shinbang-1-gill 114, Chungnam 331-801, Korea
}

\begin{abstract}
The present study investigated the contribution of carcass traits on carcass prices of Holstein steers in Korea. Phenotypic data consisted of 76,814 slaughtered Holsteins (1 to $6 \mathrm{yrs}$ ) from all over Korea. The means for live body weight at slaughter (BWT), chilled carcass weight (CWT), dressing percentage (DP), quantity grade index (QGI), eye muscle area (EMA), backfat thickness (BF) and marbling score (MS), carcass unit price (CUP), and carcass sell prices (CSP) were 729.0 kg, 414.2 kg, 56.79\%, 64.42, 75.26 $\mathrm{cm}^{2}, 5.77 \mathrm{~mm}, 1.98,8,952.80$ Korean won/kg and 3,722.80 Thousand Korean won/head. Least squares means were significantly different by various age groups, season of slaughter, marbling scores and yield grades. Pearson's correlation coefficients of CUP with carcass traits ranged from 0.12 to 0.62 . Besides, the relationships of carcass traits with CSP were relatively stronger than those with CUP. The multiple regression models for CUP and CSP with carcass traits accounted 39 to $63 \%$ of the total variation, respectively. Marbling score had maximum economic effects (partial coefficients) on both prices. In addition, the highest standardized partial coefficients (relative economic weights) for CUP and CSP were calculated to be on MS and CWT by 0.608 and 0.520 , respectively. Path analyses showed that MS (0.376) and CWT (0.336) had maximum total effects on CUP and CSP, respectively; whereas BF contributed negatively. Further sub-group (age and season of slaughter) analyses also confirmed the overall outcomes. However, the relative economic weights and total path contributions also varied among the animal sub-groups. This study suggested the significant influences of carcass traits on carcass prices; especially MS and CWT were found to govern the carcass prices of Holstein steers in Korea. (Key Words: Carcass Weight, Marbling Score, Carcass Unit Price, Carcass Sell Price, Holstein Steer)
\end{abstract}

\section{INTRODUCTION}

In Korea, Holstein steers are good alternative sources of income for alert cattle feeders. These steers contribute about $12 \%$ of total cattle slaughtered (Cho et al., 2012) in domestic beef production. However, the traditional biases in cattle marketing also accounts for some of the discount for these Holstein carcasses. This is not only because of meat quality differences, but also Korean consumers prefer the local beef breed (also known as Hanwoo cattle) for their high marbling and better flavor as locally believed. As Holsteins were developed for dairy purpose, a functional trade-off in beef quality is somewhat inevitable with a great difference in the deposition of intramuscular fat (marbling) and external fat. Yet, these steers are advantageous over Hanwoo beef cattle in regard to easier nutritional management, such that these are uniform in performance (due to narrow genetic basis) with more consistent and,

\footnotetext{
* Corresponding Author: Tae-Jeong Choi. Tel: +82-41-580-3372, Fax: +82-41-580-3369, E-mail: choi6695@korea.kr

${ }^{1}$ Korea Institute for Animal Products Quality Evaluation, 435010, Korea

Submitted Feb. 20, 2013; Accepted Apr. 11, 2013; Revised May 26, 2013
}

predictable feed intake and daily gain throughout the feeding period. Often, their faster growth than Hanwoo breeds (when gain is expressed on a live weight basis) can attract the cattle feeders.

However, the carcass traits are important meat quality determinants which directly shape the price of a carcass. A report noted that carcass traits (i.e. hot carcass weight, longissimus muscle area, 12th rib fat thickness, and marbling score) accounted $76 \%$ of the differences in carcass value (Bishop et al., 2002). It has also been indicated that pricing values significantly outweigh production and management variables in explaining profit differences among pens of cattle (Schroeder et al., 1993; Lawrence et al., 1999; Pritchard, 1999). For this reason, the Korean cattle improvement plan (MFAFF, 2008) emphasizes carcass weight (CWT), eye muscle area (EMA), and marbling score (MS) on the basis of current back fat thickness (BF). The Korean beef grading system also considers both quantity and quality grades to determine price. Quantity grade reflects the amount of saleable meat obtained by CWT, BF and EMA, whereas quality grade indicates five categorical traits (marbling, fat color, meat color, firmness, and maturity) with marbling a greater 
priority. Similar criteria are applied to determine carcass prices of other cattle breeds as most local beef consumers prefers more marbling. This preference reinforces a farmer's effort to increase marbling to obtain a higher carcass price from their animals to ensure a maximum outcome (Kim et al., 2010a). Holstein feeders also take it as a challenge to attain better marbling scores through feeding steers in an intensive concentrate feed based fattening program. However, there are no studies yet to unravel the Holstein price and market relationship in regard to its meat grades.

This present study was aimed to identify the important carcass traits in Holstein steers and their influences on carcass end prices in Korea.

\section{MATERIALS AND METHODS}

\section{Animals and traits under study}

A total of 76,814 Holstein steers that were slaughtered from March 2008 to January 2011 in various slaughter houses of Korea were subjected to this study. Steers were aged between 1 to 6 yrs and were usually castrated at their early age ( $\sim 6$ months) and, fed with commercial concentrates together with rice straw during fattening as a common practice. Pre- and post-slaughter measurements on animals were performed by following standard industrial procedures as suggested by the Ministry for Agriculture, Food and Rural Affairs (MAFRA, 2011). Animals on their arrival were weighed for live body weight (BWT) and allowed an over-night free access to drinking water. Next morning after being slaughtered (stunned followed by bleeding through the jugular vein), the carcasses were dressed in a standard method, such as removal of head, skin, viscera, and feet and, cut into two equal portions. The halved carcasses, chilled at $0^{\circ} \mathrm{C}$ for overnight, were graded by professional graders. A carcass weight (CWT) indicated the total weight of the two halves. The eye muscle (rib eye) area, EMA $\left(\mathrm{cm}^{2}\right)$, backfat thickness, BF $(\mathrm{mm})$, and marbling scores. MS (1-9) were determined from crosssection on the left half of whole carcass at a position in between the last thoracic and first lumbar vertebrae. Marbling score was classified according to the Korean Beef Marbling Standard (MAFRA, 2011) in which higher values of MS indicated the most desired carcasses. After grading, the complete carcasses were sent to an auction hall for pricing by auctioneers. Carcass unit auction price per $\mathrm{kg}$ of carcass weight (CUP) was used to determine total carcass sell price (CSP) for each animal which was a multiplication of CUP by CWT. Dressing percent (DP) represented the ratio of live weight to dressed weight. Quantity grade index (QGI) was determined as a function of BF, EMA and CWT, where QGI = 68.184-0.625BF+0.130EMA-0.024CWT (MAFRA, 2011). Thus, yield grade (YDG) was classified as
A, B and C category from QGI $\geq 67.2,>63.3$ to 67.1 and $\leq 63.3$, respectively.

\section{Statistical analysis}

Residuals, correlations and least square means: A SAS GLM procedure (SAS version 9.2) was applied to preadjust the animal phenotypes for birth year, season of birth, slaughter period (year and season), age at slaughter and slaughter house to obtain the residuals on all traits. Seasons considered in the study were winter (December to February), spring (March to May), summer (June to August), and autumn (September to November). Pearson's correlations coefficients on residuals were obtained by PROC CORR procedure in SAS. The QGI being a function of CWT, EMA and $\mathrm{BF}$ was not considered in correlation and later in path analysis. Besides that the least square means on all studied traits were also derived on age group, season of slaughter, marbling score and yield grade after fitting the respective grouping factor together with factors used in earlier GLM model for residuals.

Multiple trait regressions: Multiple trait regression analyses were performed on both price traits to estimate partial and standardized partial regression coefficients treating all carcass traits as independent variable and carcass prices as dependent traits (see Eq. 1). Partial regression coefficient for an independent variable denotes the amount of response to a dependent variable while the rest of the independent variables were held constant. The amount of variations in CUP and CSP explained by each carcass traits (i.e. partial $\mathrm{R}^{2}$ ) were determined using a stepwise selection method in GLM procedure.

$$
\begin{aligned}
\mathrm{Y}_{i j k l m}= & \mu+b_{1} \mathrm{CWT}_{i}+b_{2} \mathrm{DP}_{j}+b_{3} \mathrm{EMA}_{k} \\
& +b_{4} \mathrm{BF}_{l}+b_{5} \mathrm{MS}_{m}+e_{i j k l m}
\end{aligned}
$$

Eq. 1

Where, $\mathrm{Y}$ is CUP and CSP, $\mu$ is the intercept, $b_{1 \text { to } 5}$ are partial regression coefficients, CWT, DP, EMA, BF and MS are explanatory variables and $e_{i j k l m}$ is the residual error term.

Also, the collinearity of all independent variables was diagnosed simultaneously with the regression analyses (using COLLIN option with PROC REG) in SAS to identify any significant collinear dependencies among the carcass traits.

Path analysis: The total path contributions of each carcass traits to influence carcass prices as a means of direct and indirect effects were calculated using the following formula:

$$
\begin{aligned}
& C_{i}=D_{i}+I N D_{i j}, \quad D_{i}=P C_{i}^{2}, \\
& I N D_{i j}=\sum_{i} \sum_{j} P C_{i} P C_{j} C C_{i j} \text { and } P C_{i(j)}=\frac{S_{k}}{S_{y}} b_{k}
\end{aligned}
$$


With, $C_{i}$ being the total contribution of carcass trait $i ; D_{i}$ being the direct effect of the carcass trait $i$; IND $D_{i j}$ being the indirect effect of trait $i$ through $j ; P C_{i(j)}$ being the standardized regression coefficients of trait $i(j)$ derived from the standard deviation $\left(S_{k}\right)$ and regression coefficient $\left(b_{k}\right)$ of kth independent variable, and the standard deviation of dependent variable $\left(S_{y}\right)$. The $C C_{i j}$ is a correlation coefficient in between trait $i$ and $j$ as well.

The standardized partial regression coefficients of the GLM analyses (i.e. PC) are equal to the path coefficients that can explain the change of standard deviation in a dependent variable occurred by the change of standard deviation in an independent variable, when all other fitted independent variables were held constant. Path coefficient (or PC) proportionally partitions the variation in carcass price due to each carcass traits via direct and indirect influences. The direct effect (D) of one carcass trait on CUP or CSP was equal to the square of the path coefficient in between a carcass trait and a carcass price, whereas, the total indirect effect (IND) was a sum of all indirect contributions of carcass traits via other carcass traits which is the product of correlation coefficients in between respective carcass traits and path coefficients of those carcass traits to a carcass price in concern (Lynch and Walsh, 1998).

\section{RESULTS AND DISCUSSION}

\section{Descriptive statistics on body weight, carcass traits and carcass prices}

A simple summary statistics on traits under the study is stated in Table 1. Holstein steers had a mean body weight (BWT) of $729.0 \mathrm{~kg}$ prior to slaughter with an average of $414.2 \mathrm{~kg}$ and $56.79 \%$ of carcass weight (CWT) and dressing percent, respectively. The quantity grade index, QGI was observed to be 64.42 and, yield grade that was derived from QGI mostly comprised of grade B (69\%). Also, the mean of marbling scores on steers was 1.98 and showed the highest coefficient of variation (CV 66\%) compared to other traits. Only $11 \%$ of Holstein steer carcasses represented higher marbling (MS 4-9), while the majority had the lowest score of MS 1 . A variability of $41 \%$ in backfat thickness (BF) with a mean of $5.77 \mathrm{~mm}$ was found as well. The observed mean of EMA in this study was $75.26 \mathrm{~cm}^{2}$. Price traits, however, varied within 21 to $26 \%$ and the mean of carcass unit price (CUP) and total carcass sell price (CSP) were 8,953 Korean Won and 3,723 thousand Korean Won, respectively.

Holsteins in Korea were reported previously by Yun et al. (1994) to have $535.2 \mathrm{~kg}$ of live weight, $293.6 \mathrm{~kg}$ of CWT, $54.8 \%$ of DP, $71.1 \mathrm{~cm}^{2}$ of rib-eye area (EMA), $2.6 \mathrm{~mm}$ of $\mathrm{BF}$, and 1.1 of MS, which we deemed to be somewhat similar or slightly lower to the observations in this study. Similar to Yun et al. (1994), Zaujec et al. (2009) also reported Slovak Pied and Holstein bulls to have a lower CWT with $54.56 \%$ DP, but varied greatly from the current estimates. However, our results of DP, BF or EMA coincided with earlier reports by Abney (2004), Knapp et al. (1989), Garrett (1971), Martin and Wilson (1974), in which Holsteins were declared to perform comparatively lower than typical beef breeds. In contrast, NLRI (2002) in Korea cited relatively larger BWT and CWT; also recorded $60.8 \%$ of DP, $6.9 \mathrm{~mm}$ of BF, $88.8 \mathrm{~cm}^{2}$ of EMA and MS of 4.0 on fattening Holstein steers at 24 months of age and, thus appeared higher than our estimates. Kim et al. (1996) also remarked that castration of Korean Holstein males improved their beef quality.

Like the other beef breeds such as Angus and American Wagyu (Lunt et al., 1993), Korean Hanwoo cattle (Baik et al., 2003; Moon et al., 2007; Hwang et al., 2008; Kim et al., 2010a,b) also differed greatly with Holstein steers in this study by showing a higher QGI, EMA, BF and MS; although, Hanwoo cattle had heavier or lighter CWT than that of Holsteins. However, the observed EMA of Hanwoo cattle in Hwang et al. (2008) was similar to the current study. Nevertheless, our steers scored a larger EMA

Table 1. Simple statistics on carcass traits and carcass prices of Holstein steers in Korea

\begin{tabular}{lccccc}
\hline Traits* & Mean & SD & Min & Max & CV \\
\hline SLAGE (d) & 699.1 & 122.9 & 364 & 2,133 & 17.6 \\
BWT (kg) & 729.0 & 78.5 & 360 & 1,076 & 10.8 \\
CWT (kg) & 414.2 & 48.8 & 184 & 639 & 11.8 \\
DP $(\%)$ & 56.79 & 2.01 & 34.50 & 50.20 & 3.5 \\
QGI & 64.42 & 2.03 & 38.21 & 71.73 & 3.2 \\
EMA $\left(\mathrm{cm}^{2}\right)$ & 75.26 & 8.41 & 1 & 113 & 11.2 \\
BF (mm) & 5.77 & 2.39 & 1 & 9 & 41.4 \\
MS & 1.98 & 1.30 & 5,800 & 15,999 & 65.6 \\
CUP (KRW) & $8,952.8$ & $1,922.4$ & 1,113 & 7,830 & 21.5 \\
CSP (thousand KRW) & $3,722.8$ & 968.8 & & 26.0 \\
\hline
\end{tabular}

* Total number of records, $\mathrm{N}=76,814 ;$ SLAGE $=$ Slaughter age; $\mathrm{BWT}=$ Body weight at slaughter day; CWT = Cold carcass weight; DP = Dressing percent; $\mathrm{QGI}=$ Quantity grade index; EMA = Eye muscle area at 13th rib; BF = Backfat thickness; MS = Marbling score; CUP = Carcass unit price at auction in Korean won; CSP $=$ Total carcass sell price in thousand Korean won. 
Table 2. Least squares means $\left( \pm \mathrm{SE}^{*}\right)$ for body weight, carcass traits and carcass prices of Holstein steers by age group

\begin{tabular}{lcccrc}
\hline & \multicolumn{5}{c}{ Age group } \\
Trait** & $1-1.5 \mathrm{yr}$ & $1.5-2 \mathrm{yr}$ & $2-2.5 \mathrm{yr}$ & $2.5-3 \mathrm{yr}$ & $>3 \mathrm{yr}$ \\
& $(\mathrm{N}=4,749)$ & $(\mathrm{N}=47,313)$ & $(\mathrm{N}=21,003)$ & $(\mathrm{N}=3,003)$ & $(\mathrm{N}=746)$ \\
\hline BWT & $630.78 \pm 8.46^{\mathrm{c}}$ & $656.87 \pm 8.43^{\mathrm{a}}$ & $653.87 \pm 8.53^{\mathrm{b}}$ & $618.57 \pm 8.84^{\mathrm{d}}$ & $553.77 \pm 9.39^{\mathrm{e}}$ \\
CWT & $350.96 \pm 5.25^{\mathrm{c}}$ & $367.44 \pm 5.23^{\mathrm{a}}$ & $365.62 \pm 5.30^{\mathrm{b}}$ & $342.88 \pm 5.48^{\mathrm{d}}$ & $303.32 \pm 5.83^{\mathrm{e}}$ \\
DP & $55.66 \pm 0.23^{\mathrm{b}}$ & $55.96 \pm 0.23^{\mathrm{a}}$ & $55.93 \pm 0.23^{\mathrm{a}}$ & $55.53 \pm 0.24^{\mathrm{b}}$ & $55.11 \pm 0.25^{\mathrm{c}}$ \\
QGI & $65.68 \pm 0.23^{\mathrm{b}}$ & $65.10 \pm 0.23^{\mathrm{d}}$ & $65.23 \pm 0.23^{\mathrm{c}}$ & $65.80 \pm 0.24^{\mathrm{b}}$ & $66.33 \pm 0.25^{\mathrm{a}}$ \\
EMA & $70.10 \pm 0.94^{\mathrm{b}}$ & $71.16 \pm 0.94^{\mathrm{a}}$ & $71.30 \pm 0.95^{\mathrm{a}}$ & $69.55 \pm 0.98^{\mathrm{b}}$ & $65.44 \pm 1.04^{\mathrm{c}}$ \\
BF & $5.10 \pm 0.27^{\mathrm{c}}$ & $5.62 \pm 0.27^{\mathrm{a}}$ & $5.52 \pm 0.27^{\mathrm{b}}$ & $5.10 \pm 0.28^{\mathrm{c}}$ & $4.93 \pm 0.30^{\mathrm{c}}$ \\
MS & $1.68 \pm 0.15^{\mathrm{b}}$ & $1.83 \pm 0.15^{\mathrm{a}}$ & $1.86 \pm 0.15^{\mathrm{a}}$ & $1.61 \pm 0.15^{\mathrm{b}}$ & $1.03 \pm 0.16^{\mathrm{c}}$ \\
CUP & $7,830.97 \pm 181.62^{\mathrm{c}}$ & $8,072.23 \pm 181.07^{\mathrm{a}}$ & $7,987.03 \pm 183.28^{\mathrm{b}}$ & $7,534.01 \pm 189.82^{\mathrm{d}}$ & $7,202.79 \pm 201.65^{\mathrm{e}}$ \\
CSP & $2,712.97 \pm 97.00^{\mathrm{c}}$ & $2,943.57 \pm 96.70^{\mathrm{a}}$ & $2,899.19 \pm 97.89^{\mathrm{b}}$ & $2,505.00 \pm 101.38^{\mathrm{d}}$ & $2,024.28 \pm 107.70^{\mathrm{e}}$ \\
\hline
\end{tabular}

* SE $=$ Standard error of mean.

** BWT = Body weight at slaughter day; CWT = Carcass weight; DP = Dressing percent; QGI = Quantity grade index; EMA = Eye muscle area at 13 th rib; $\mathrm{BF}=$ Backfat thickness; $\mathrm{MS}=$ Marbling score; CUP $=$ Carcass unit price at auction in Korean won; CSP $=$ Total carcass sell price in thousand Korean won.

${ }^{1}$ Means differed significantly at $\mathrm{p}<0.05$.

compared to the relatively heavier Japanese beef breeds (Ibi et al., 2006; Kahi et al., 2007) despite them having a higher $\mathrm{BF}$ and MS. The CV estimates in Holstein carcass also compares favorably with Korean cattle (Moon et al., 2007; Hwang et al., 2008; Kim et al., 2010a), Japanese Brown cattle (Kahi et al., 2007), Hereford cattle (Galli et al., 2008), or with Brahman, Angus, Limousin cattle (Rios-Utrera et al., 2005; Smith et al., 2007). However, the greater CV in marbling score in this study could be due to a familiar situation in Korea where animals are stall fed and hence, have less access to pasture during the fattening regimen. Otherwise, it could be feasible that the differences in technique used to score marbling, as also agreed by Kim et al. (2010a), was a cause of the variations between the studies.

Least squares means of body weight, carcass traits and

\section{carcass prices}

Table 2 to 5 represent the least squares means (LSMEANS) by age group, season of slaughter, marbling score and yield grade, respectively. The means for most traits based on age groups were usually higher at 1.5 to 2 years for Holsteins except QGI being the lowest. Besides, statistically similar LSMEANS of DP, EMA and MS were observed between 1.5 to $2 \mathrm{yr}$ and 2 to $2.5 \mathrm{yr}$ age groups and, for animals that were aged within 1 to 1.5 and 2.5 to $3 \mathrm{yrs}$. In contrast, LSMEANS of BWT, CWT, CUP and CSP differed in all age groups. According to Table 3, animals slaughtered during winter had the highest LSMEANS for BWT, CWT, EMA, BF and price traits. Marbling score had similar LSMEANS in most seasons except for summer. Also the LSMEANS by MS (Table 4) for BWT, CWT, DP, and BF mostly differed at lower scores whereas, they were similar at MS 4 or above. A higher MS was also

Table 3. Least squares means $( \pm$ SE*) of for body weight, carcass traits and carcass prices of Holstein steers by season of slaughter

\begin{tabular}{|c|c|c|c|c|}
\hline \multirow[b]{2}{*}{ Trait** } & \multicolumn{4}{|c|}{ Season of slaughter $^{1}$} \\
\hline & $\begin{array}{c}\text { Winter } \\
(\mathrm{N}=18,452)\end{array}$ & $\begin{array}{c}\text { Spring } \\
(\mathrm{N}=15,819)\end{array}$ & $\begin{array}{c}\text { Summer } \\
(\mathrm{N}=20,044)\end{array}$ & $\begin{array}{c}\text { Autumn } \\
(\mathrm{N}=22,499)\end{array}$ \\
\hline$\overline{\mathrm{BWT}}$ & $641.70 \pm 8.50^{\mathrm{a}}$ & $630.90 \pm 8.50^{c}$ & $636.10 \pm 8.50^{\mathrm{b}}$ & $635.72 \pm 8.52^{\mathrm{b}}$ \\
\hline CWT & $357.04 \pm 5.28^{\mathrm{a}}$ & $352.26 \pm 5.28^{\mathrm{b}}$ & $356.08 \pm 5.28^{\mathrm{a}}$ & $356.48 \pm 5.29^{\mathrm{a}}$ \\
\hline DP & $55.70 \pm 0.23^{\mathrm{d}}$ & $55.88 \pm 0.23^{\mathrm{c}}$ & $56.00 \pm 0.23^{\mathrm{b}}$ & $56.10 \pm 0.23^{\mathrm{a}}$ \\
\hline QGI & $65.27 \pm 0.23^{\mathrm{b}}$ & $65.39 \pm 0.23^{\mathrm{a}}$ & $65.38 \pm 0.23^{\mathrm{a}}$ & $65.25 \pm 0.23^{\mathrm{b}}$ \\
\hline EMA & $70.40 \pm 0.93^{\mathrm{a}}$ & $69.58 \pm 0.93^{\mathrm{d}}$ & $69.77 \pm 0.94^{\mathrm{c}}$ & $69.96 \pm 0.94^{\mathrm{b}}$ \\
\hline $\mathrm{BF}$ & $5.59 \pm 0.27^{\mathrm{a}}$ & $5.41 \pm 0.27^{\mathrm{b}}$ & $5.32 \pm 0.27^{\mathrm{c}}$ & $5.55 \pm 0.27^{\mathrm{a}}$ \\
\hline MS & $1.62 \pm 0.15^{\mathrm{b}}$ & $1.64 \pm 0.15^{\mathrm{b}}$ & $1.68 \pm 0.15^{\mathrm{a}}$ & $1.61 \pm 0.15^{\mathrm{b}}$ \\
\hline CUP & $8,357.11 \pm 176.45^{\mathrm{a}}$ & $7,864.59 \pm 176.43^{\mathrm{b}}$ & $7,334.50 \pm 176.57^{\mathrm{d}}$ & $7,708.05 \pm 176.96^{\mathrm{c}}$ \\
\hline CSP & $2,976.43 \pm 95.67^{\mathrm{a}}$ & $2,723.91 \pm 95.66^{\mathrm{b}}$ & $2,540.30 \pm 95.73^{\mathrm{d}}$ & $2,696.20 \pm 95.95^{\mathrm{c}}$ \\
\hline
\end{tabular}

* SE $=$ Standard error of mean.

** BWT = Body weight at slaughter day; CWT = Carcass weight; DP = Dressing percent; QGI = Quantity grade index; EMA = Eye muscle area at 13th rib; $\mathrm{BF}=$ Backfat thickness; $\mathrm{MS}=$ Marbling score; CUP $=$ Carcass unit price at auction in Korean won; CSP $=$ Total carcass sell price in thousand Korean won.

${ }^{1}$ Means differed significantly at $\mathrm{p}<0.05$ 
Table 4. Least squares means ( $\left.\pm \mathrm{SE}^{*}\right)$ of for body weight, carcass traits and carcass prices by marbling score

\begin{tabular}{lccccc}
\hline & \multicolumn{5}{c}{ Marbling score $^{\mathrm{l}}$} \\
\cline { 2 - 6 } Trait** & 1 & 2 & 3 & $5-9$ \\
& $(\mathrm{~N}=36,733)$ & $(\mathrm{N}=21,201)$ & $(\mathrm{N}=10,079)$ & $(\mathrm{N}=4,097)$ & $(\mathrm{N}=4,704)$ \\
\hline BWT & $623.23 \pm 8.18^{\mathrm{d}}$ & $659.08 \pm 8.20^{\mathrm{c}}$ & $661.96 \pm 8.21^{\mathrm{b}}$ & $674.25 \pm 8.25^{\mathrm{a}}$ & $672.66 \pm 8.25^{\mathrm{a}}$ \\
CWT & $345.66 \pm 5.03^{\mathrm{d}}$ & $369.85 \pm 5.04^{\mathrm{c}}$ & $372.40 \pm 5.05^{\mathrm{b}}$ & $381.43 \pm 5.08^{\mathrm{a}}$ & $380.87 \pm 5.07^{\mathrm{a}}$ \\
DP & $55.57 \pm 0.22^{\mathrm{d}}$ & $56.12 \pm 0.22^{\mathrm{c}}$ & $56.24 \pm 0.22^{\mathrm{b}}$ & $56.50 \pm 0.22^{\mathrm{a}}$ & $56.55 \pm 0.22^{\mathrm{a}}$ \\
QGI & $65.74 \pm 0.22^{\mathrm{a}}$ & $64.66 \pm 0.22^{\mathrm{b}}$ & $64.64 \pm 0.22^{\mathrm{b}}$ & $64.20 \pm 0.22^{\mathrm{c}}$ & $64.37 \pm 0.22^{\mathrm{d}}$ \\
EMA & $69.28 \pm 0.93^{\mathrm{e}}$ & $70.55 \pm 0.93^{\mathrm{d}}$ & $71.20 \pm 0.93^{\mathrm{c}}$ & $72.13 \pm 0.93^{\mathrm{b}}$ & $73.14 \pm 0.93^{\mathrm{a}}$ \\
BF & $5.03 \pm 0.26^{\mathrm{d}}$ & $6.10 \pm 0.26^{\mathrm{c}}$ & $6.18 \pm 0.26^{\mathrm{b}}$ & $6.73 \pm 0.26^{\mathrm{a}}$ & $6.69 \pm 0.26^{\mathrm{a}}$ \\
CUP & $7,369.49 \pm 141.70^{\mathrm{e}}$ & $8,679.32 \pm 141.94^{\mathrm{d}}$ & $8,897.58 \pm 142.19^{\mathrm{c}}$ & $10,084.41 \pm 142.94^{\mathrm{b}}$ & $10,596.51 \pm 142.83^{\mathrm{a}}$ \\
CSP & $2,462.82 \pm 75.76^{\mathrm{e}}$ & $3,208.10 \pm 75.89^{\mathrm{d}}$ & $3,326.58 \pm 76.02^{\mathrm{c}}$ & $3,928.97 \pm 76.42^{\mathrm{b}}$ & $4,157.08 \pm 76.36^{\mathrm{a}}$ \\
\hline
\end{tabular}

* SE $=$ Standard error of mean.

** BWT = Body weight at slaughter day; CWT = Carcass weight; DP = Dressing percent; QGI = Quantity grade index; EMA = Eye muscle area at 13th rib; $\mathrm{BF}=$ Backfat thickness; $\mathrm{MS}=$ Marbling score; CUP = Carcass unit price at auction in Korean won; CSP = Total carcass price in thousand Korean won.

${ }^{1}$ Means differed significantly at $\mathrm{p}<0.05$.

accompanied by greater BWT, CWT, EMA, BF, and CSP. Further, yield grade (YDG) analysis indicated significantly different LSMEANS in all sub-categories for all traits (Table 5).

The lowest carcass price despite higher MS was found during summer (Table 3 ) which seemingly contradicts the results in Table 2 and 4 in which higher MS were usually tabulated with higher price values and other carcass traits. Typically winter is critical for animals in terms of feed abundance due increased feed cost as well as reduced growth due to extra energy requirements to thrive on. Oppositely, consumer demands usually elevates because of increased sociocultural activities in Korea in winter. Therefore, a comparatively lower quality carcass fetches a relatively high price due to increased demand for beef. However, the higher CWT and BF or the lower EMA in yield grade ' $\mathrm{C}$ ' evidently justifies the equation that derived
QGI and subsequently YDG (see Materials and Methods), denoting that a carcass with higher CWT and BF would potentially have a lower QGI due to negative function effect of BF and CWT, and thus a lower YDG of that carcass; whereas higher EMA values would imply more weight to derive a higher QGI (due to positive function effect) or higher yield grades.

\section{Pearson's correlations on body weight, carcass traits and carcass prices}

Pearson's correlation coefficients on residuals of carcass traits and carcass prices (Table 6) show that marbling score had relatively stronger effect on both carcass unit price $(0.62)$ and carcass sell price $(0.61)$. This indicated a distinct interrelation of MS and the Korean beef market. However, the relationships of CSP and carcass traits were found stronger than those with CUP and other traits. Note that the

Table 5. Least squares means $\left( \pm \mathrm{SE}^{*}\right)$ of for body weight, carcass traits and carcass prices of Holstein steers by yield grade

\begin{tabular}{lccc}
\hline & \multicolumn{3}{c}{ Yield grade $^{1}$} \\
\cline { 2 - 4 } Trait** & $\mathrm{A}$ & $\mathrm{B}$ & $\mathrm{C}$ \\
& $(\mathrm{N}=3,948)$ & $(\mathrm{N}=53,168)$ & $703.05 \pm 7.60^{\mathrm{a}}$ \\
\hline BWT & $566.70 \pm 7.64^{\mathrm{c}}$ & $640.01 \pm 7.59^{\mathrm{b}}$ & $398.95 \pm 4.64^{\mathrm{a}}$ \\
CWT & $311.32 \pm 4.67^{\mathrm{c}}$ & $356.43 \pm 4.64^{\mathrm{b}}$ & $56.66 \pm 0.22^{\mathrm{a}}$ \\
DP & $55.15 \pm 0.22^{\mathrm{c}}$ & $55.77 \pm 0.22^{\mathrm{b}}$ & $62.02 \pm 0.13^{\mathrm{c}}$ \\
QGI & $67.92 \pm 0.13^{\mathrm{a}}$ & $65.41 \pm 0.13^{\mathrm{b}}$ & $68.60 \pm 0.93^{\mathrm{c}}$ \\
EMA & $73.24 \pm 0.93^{\mathrm{a}}$ & $69.38 \pm 0.93^{\mathrm{b}}$ & $8.81 \pm 0.19^{\mathrm{a}}$ \\
BF & $3.70 \pm 0.19^{\mathrm{c}}$ & $5.17 \pm 0.19^{\mathrm{b}}$ & $2.15 \pm 0.14^{\mathrm{a}}$ \\
MS & $1.19 \pm 0.14^{\mathrm{c}}$ & $1.66 \pm 0.14^{\mathrm{b}}$ & $8,274.30 \pm 179.77^{\mathrm{a}}$ \\
CUP & $7,408.97 \pm 180.65^{\mathrm{c}}$ & $8,036.36 \pm 179.47^{\mathrm{b}}$ & $3,302.72 \pm 92.50^{\mathrm{a}}$ \\
CSP & $2,206.24 \pm 92.95^{\mathrm{c}}$ & $2,829.38 \pm 92.35^{\mathrm{b}}$ & \\
\hline
\end{tabular}

* SE $=$ Standard error of mean

** BWT = Body weight at slaughter day; $\mathrm{CWT}=$ Carcass weight; DP = Dressing percent; $\mathrm{QGI}=$ Quantity grade index; EMA = Eye muscle area at 13 th rib; $\mathrm{BF}=$ Backfat thickness; $\mathrm{MS}=$ Marbling score; $\mathrm{CUP}=$ Carcass unit price at auction in Korean won; CSP $=$ Total carcass sell price in thousand Korean won.

${ }^{1}$ Means differed significantly at $\mathrm{p}<0.05$. 
Table 6. Pearson's correlation coefficient on residuals of carcass traits and carcass prices of Holstein steers

\begin{tabular}{llcccccc}
\hline Trait ${ }^{*, 1}$ & CWT & DP & EMA & BF & MS & CUP & CSP \\
\hline BWT & 0.95 & 0.13 & 0.48 & 0.36 & 0.22 & 0.20 & 0.60 \\
CWT & & 0.42 & 0.52 & 0.41 & 0.25 & 0.22 & 0.65 \\
DP & & & 0.28 & 0.24 & 0.16 & 0.14 & 0.31 \\
EMA & & & 0.18 & 0.14 & 0.16 & 0.37 \\
BF & & & & 0.23 & 0.12 & 0.28 \\
MS & & & & & 0.62 & 0.61 \\
CUP & & & & & & 0.88 \\
\hline
\end{tabular}

* All correlations differed significantly at $\mathrm{p}<0.001$.

${ }^{1}$ BWT = Body weight at slaughter day; CWT = Carcass weight DP = Dressing percent; QGI = Quantity grade index; EMA = Eye muscle area at 13 th rib; $\mathrm{BF}=$ Backfat thickness; MS = Marbling score CUP = Carcass unit price at auction in Korean won; CSP = Total carcass sell price in thousand Korean won.

strongest and weakest correlations among carcass traits were in between CWT and EMA (0.52), and EMA and MS (0.14), respectively. Price traits also showed a correlation of 0.88 within themselves.

The strong positive relationship in between CUP and MS clearly indicates that marbling score is the key determinant to carcass value; which was similar to the price effect of Hanwoo cattle (Kim et al., 2010a,b) or Japanese Black Cattle (Ibi et al., 2006; Kahi et al., 2007). The result of Zaujec et al. (2009) supports the present result of a positive relationship of dressing percent with increased carcass weight in Holstein. Yun et al. (1994) who reported a positive relationship of CWT with $\mathrm{BF}$ and rib-eye area in a study on Korean Holstein population also fits with our study showing the positive correlations between BF and MS and, auction price (or CUP) and MS. More agreement was depicted in Pyatt et al. (2005) by the simple linear correlation between carcass values and carcass weight (0.24) and, between marbling score (0.51) despite some differences in magnitude of the relationships. However, the residual correlations in between MS and DP (-0.04), MS and rib-eye (-0.12) and, DP and rib-eye area (0.29) of Hanwoo cattle study in Lee et al. (2000) using animal models was somewhat closer to our results except that there is no negative correlation in our study. The correlations among MS, BF and CWT in this study were consistent with the positive link of better quality grades (MS) and carcass weight in Hanwoo steers (Park et al., 2002; Moon et al., 2003), the tendency of better USDA quality grade with higher carcass weight in beef breeds (Lorenzen et al., 1993) or a fatter carcass in dairy cattle and Bos indicus breeds (Kauffman et al., 1975; Abraham et al., 1980; Griffin, 1992; Jeremiah, 1996; Dikeman et al., 1998). Slightly lower or similar results of environmental correlations were also estimated in various beef breeds by Rios-Utrera et al. (2005) for hot-carcass weight, dressing percent, adjusted fat thickness, LM-area (longissimus thoracis et lumborum muscle) and MS. Nonetheless, the lower phenotypic correlations (<0.30) mentioned in Smith et al. (2007) for Brahman steers coincided with those in the current study as well.

\section{Regression coefficients and path contributions of carcass traits on carcass prices}

The partial regression coefficients (PRC), standardized partial regression coefficients (standard PRC) and the coefficient of determination $\left(\mathrm{R}^{2}\right)$ values on residuals of each carcass traits are tabulated in Table 7. Multiple linear models regressing carcass traits on carcass prices explained about $39.19 \%$ and $63.27 \%$ of the existing variations in CUP and CSP, respectively. The $\mathrm{F}$ values in these models were significant at $\mathrm{p}<0.0001$. Diagnosis of independent variables also confirmed no significant collinearity among them. It can be seen that marbling score was the prime determinant of CUP (partial $\mathrm{R}^{2}=0.38$ ) as well as contributing significantly to CSP. In contrast, CSP was basically influenced by CWT $\left(\mathrm{R}^{2}=0.42\right)$. Carcass unit price had a regression coefficient of $732.65 \mathrm{KRW}$ (Korean Won) from MS and a negative coefficient of $-42.07 \mathrm{KRW}$ from $\mathrm{BF}$. Therefore, if the PRC value i.e. $732.65 \mathrm{KRW}$ is considered to be the indicator of economic value of the respective trait (MS), it essentially indicates a unit positive change in MS that adds an increment of worth by $732.65 \mathrm{KRW}$ to the CUP while the rest of the independent variables are held constant. Thus, it is evident in Holstein steers that a one unit rise in MS can increase the CSP by $314,340 \mathrm{KRW}$. Also, it was found that higher values in most of the carcass traits generally accounted for positive changes in prices except BF.

On the other hand, the highest standardized partial regression coefficient of MS and CWT to CUP and CSP were 0.608 and 0.481 , respectively. These standard PRCs could be considered as equivalent to their relative economic weight while other carcass traits were held constant. Also, the absolute standard PRC for MS and CWT obtained in this study suggested their relative importance in determining the Holstein beef price in Korea and, hence revealed their major influences on CUP and CSP, respectively. Oppositely, the negative relative economic value of $\mathrm{BF}$ indicated a lower preference while making 
Table 7. Estimates of partial regression coefficients of carcass traits on carcass prices

\begin{tabular}{llccc}
\hline Price & Trait & Partial coefficient $^{1}$ & Standardized partial & Partial R $^{2}$ \\
\hline CUP & CWT & $1.92 \pm 0.13$ & 0.0573 & 0.0025 \\
& DP & $15.44 \pm 2.45$ & 0.0198 & 0.0003 \\
& EMA & $9.64 \pm 0.62$ & 0.0511 & 0.0055 \\
& BF & $-42.07 \pm 2.06$ & -0.0637 & 0.0017 \\
& MS & $732.65 \pm 3.55$ & 0.6080 & 0.3818 \\
& $\mathrm{R}^{2, * *}$ & & & 0.3919 \\
CSP & CWT & $9.42 \pm 0.05$ & 0.5198 & 0.4182 \\
& DP & $7.74 \pm 1.03$ & 0.0182 & 0.0003 \\
& EMA & $3.76 \pm 0.26$ & 0.0367 & 0.0011 \\
& BF & $-19.79 \pm 0.87$ & -0.0553 & 0.0025 \\
MS & $314.34 \pm 1.49$ & 0.4811 & 0.2107 \\
& & & & 0.6327
\end{tabular}

* CWT = Carcass weight; DP = Dressing percent; QGI = Quantity grade index; EMA $=$ Eye muscle area at 13th rib; BF = Backfat thickness; MS = Marbling score; $\mathrm{CUP}=$ Carcass unit price at auction in Korean won; $\mathrm{CSP}=$ Total carcass sell price in thousand Korean won.

$* * \mathrm{R}^{2}=$ Coefficient of determination for the multiple regression models.

${ }^{1}$ All variables were significant at $\mathrm{p}<0.0001$ to CUP and CSP.

price decisions on steer carcass (Table 7). In other words, the higher BF was rewarded with relatively lesser prices. Note that, the negative PRC of BF to CUP or CSP and the greater LSMEANS of CUP or CSP at higher CWT, MS or $\mathrm{BF}$ which was mentioned earlier is not a contradiction, but indicates a fact that higher prices were mostly obtained by a higher MS or CWT except with a higher BF. The weakest correlations of $\mathrm{BF}$ and carcass prices, even though $\mathrm{BF}$ strongly associated to other carcass traits (Table 6), also signifies the negative PRC and standard PRC of BF on CUP and CSP.

Table 8 and Figure 1 narrate the total, direct and indirect path contributions of each carcass trait to price traits. It is revealed that the total path contribution of MS on CUP (0.3757) was clearly dominating over others; whereas, it almost equally shared with the effects of CWT on CSP.
Table 9 further shows that carcass weight received more relative economic weight at younger age with a gradual decrease as age progressed and, thus incorporated the highest contribution to all prices at younger animals. An opposite was found in MS for which relative economic values uplifted until 3 years of age and remained stable or slightly lower in relatively older animals (3 to $6 \mathrm{yrs}$ ). So, the contribution of MS is higher within 1. 5 to $6 \mathrm{yrs}$ being opposite to CWT. The relative economic weights of carcass weight and marbling score on prices were the highest in spring and summer, respectively (Table 9). As a price decline in summer regardless of carcass quality was noticed earlier (Table 3), this maximum relative economic weight was an indication of an added effort to increase MS as a means of restoring the carcass price based on a better quality carcass. Also note that the path influences of MS on

Table 8. Path contributions of carcass traits on carcass prices of Holstein males

\begin{tabular}{llrrrrr}
\hline Price & Variable $^{1}$ & CWT & DP & EMA & \multicolumn{1}{c}{ BF } & MS \\
\hline CUP & CWT & 0.0033 & 0.0005 & 0.0015 & -0.0015 & 0.0089 \\
& DP & 0.0005 & 0.0004 & 0.0003 & -0.0003 & 0.0019 \\
& EMA & 0.0015 & 0.0003 & 0.0026 & -0.0006 & 0.0043 \\
& BF & -0.0015 & -0.0003 & -0.0006 & 0.0041 & -0.0090 \\
& MS & 0.0089 & 0.0019 & 0.0043 & -0.0090 & 0.3696 \\
CSP & TC & 0.0127 & 0.0028 & 0.0081 & -0.0073 & 0.3757 \\
& CWT & 0.2702 & 0.0040 & 0.0100 & -0.0117 & 0.0636 \\
& DP & 0.0040 & 0.0003 & 0.0002 & -0.0002 & 0.0014 \\
& EMA & 0.0100 & 0.0002 & 0.0013 & -0.0004 & 0.0024 \\
& BF & -0.0117 & -0.0002 & -0.0004 & 0.0031 & -0.0062 \\
& MS & 0.0636 & 0.0014 & 0.0024 & -0.0062 & 0.2314 \\
& TC & 0.3362 & 0.0057 & 0.0136 & -0.0154 & 0.2927
\end{tabular}

${ }^{1}$ BWT = Body weight at slaughter day; CWT = Carcass weight; DP = Dressing percent; QGI = Quantity grade index; EMA = Eye muscle area at 13th rib; $\mathrm{BF}=$ Backfat thickness; MS = Marbling score; CUP $=$ Carcass unit price at auction in Korean won; $\mathrm{CSP}=$ Total carcass sell price in thousand Korean won.

${ }^{2} \mathrm{TC}=$ Total path contribution for each independent variable. 


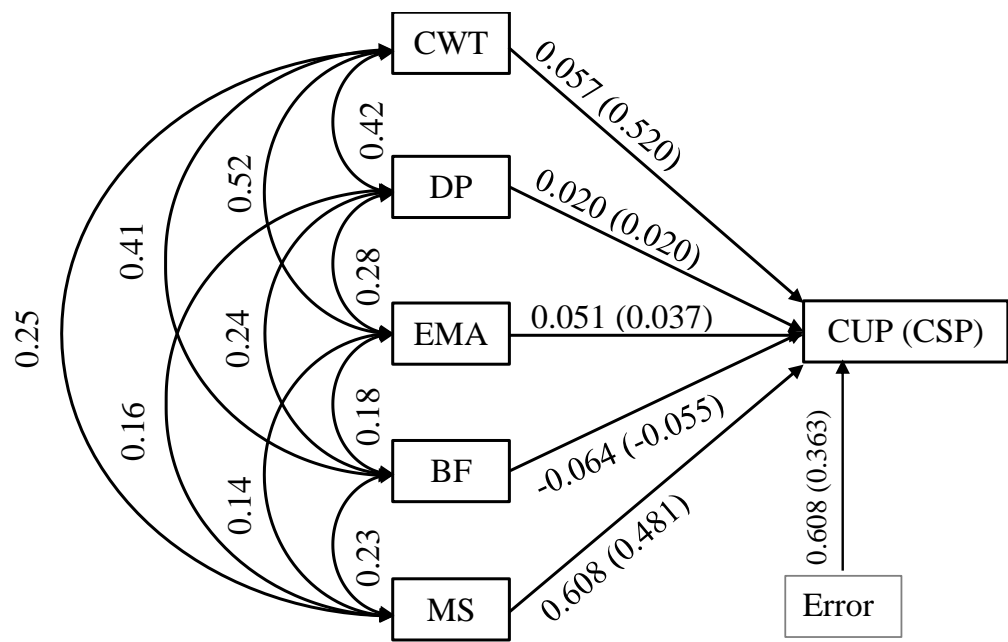

Figure 1. Path diagram illustrates the direct and indirect routes of influences from carcass traits on carcass prices of Holstein steers. Numbers along the single-headed arrows are path coefficients; whereas, the double headed arrows depict the strength of relationship among these traits $(\mathrm{CWT}=$ Carcass weight; $\mathrm{DP}=$ Dressing percent; $\mathrm{EMA}=$ Eye muscle area at 13 th rib; $\mathrm{BF}=\mathrm{Backfat}$ thickness; MS $=$ Marbling score; CUP $=$ Carcass unit price at auction in Korean won; CSP $=$ Total carcass sell price in thousand Korean won; Error $=$ Error in statistical model)

per unit carcass price were consistently higher (Figures 2 and 3). In contrast, the relative economic weights mostly varied for CUP, which is less for CSP (Table 9). The consistent relative economic weight of CSP could be due to a cumulative contribution from heavier and homogeneous carcasses of steers together with the higher correlation of CWT and CSP (Table 6); making the changes in CSP more predictable than CUP. For this reason, the total effect of CWT always surpassed the effect of MS on CSP even though MS was given prime economic importance to per kilogram beef price at any given age or season.
However, it appears that our results of marbling score of Holsteins in Korea was in concordance with Korean Hanwoo cattle (Kim et al., 2010a,b; Moon et al., 2007). Similarly, some negative standardized economic weights for fat thickness (Table 7) were also observed by Ibi et al. (2006) on Japanese cattle. This negative weight revealed that in overall profitability there was less contribution from undesired BF. As higher BF is unavoidable at heavier carcasses (Table 6), a negative constraint against higher backfat thickness of heavier carcasses somehow avoided a mistranslated profit due to excessive $\mathrm{BF}$ and a true higher

Table 9. Relative economic weight observed on different age groups (AGR), seasons of slaughter (SSL) and year of slaughter (YSL)

\begin{tabular}{|c|c|c|c|c|c|c|c|c|c|}
\hline \multirow{2}{*}{\multicolumn{2}{|c|}{ Criterion/trait* }} & \multicolumn{4}{|c|}{ CWT } & \multicolumn{4}{|c|}{ MS } \\
\hline & & \multicolumn{2}{|c|}{$\mathrm{SP}^{1}$} & \multicolumn{2}{|c|}{$\mathrm{TC}^{2}$} & \multicolumn{2}{|c|}{ SP } & \multicolumn{2}{|c|}{ TC } \\
\hline & & CUP & CSP & CUP & CSP & CUP & CSP & CUP & CSP \\
\hline \multirow[t]{5}{*}{ AGR } & $1-1.5 \mathrm{yr}$ & 0.25 & 0.68 & 0.105 & 0.533 & 0.51 & 0.36 & 0.298 & 0.199 \\
\hline & $1.5-2 \mathrm{yr}$ & 0.09 & 0.53 & 0.021 & 0.346 & 0.64 & 0.50 & 0.415 & 0.311 \\
\hline & $2-2.5 \mathrm{yr}$ & 0.03 & 0.50 & 0.005 & 0.321 & 0.63 & 0.50 & 0.396 & 0.311 \\
\hline & $2.5-3 \mathrm{yr}$ & 0.00 & 0.51 & 0.001 & 0.340 & 0.67 & 0.51 & 0.448 & 0.331 \\
\hline & $>3 \mathrm{yr}$ & -0.04 & 0.53 & -0.007 & 0.358 & 0.62 & 0.47 & 0.375 & 0.303 \\
\hline \multirow[t]{4}{*}{ SSL } & Winter & 0.03 & 0.50 & 0.006 & 0.318 & 0.57 & 0.46 & 0.329 & 0.266 \\
\hline & Spring & 0.13 & 0.62 & 0.039 & 0.456 & 0.69 & 0.49 & 0.490 & 0.308 \\
\hline & Summer & 0.10 & 0.56 & 0.030 & 0.396 & 0.73 & 0.55 & 0.557 & 0.379 \\
\hline & Autumn & 0.09 & 0.55 & 0.023 & 0.378 & 0.69 & 0.53 & 0.486 & 0.345 \\
\hline \multirow[t]{4}{*}{ YSL } & 2008 & -0.05 & 0.43 & -0.011 & 0.281 & 0.85 & 0.66 & 0.715 & 0.516 \\
\hline & 2009 & 0.13 & 0.58 & 0.042 & 0.421 & 0.69 & 0.51 & 0.496 & 0.337 \\
\hline & 2010 & 0.09 & 0.56 & 0.025 & 0.390 & 0.69 & 0.52 & 0.490 & 0.345 \\
\hline & 2011 & 0.04 & 0.53 & 0.007 & 0.346 & 0.64 & 0.50 & 0.410 & 0.305 \\
\hline
\end{tabular}

* CWT = Carcass weight; MS = Marbling score; CUP = Carcass unit price at auction in Korean won; CSP = Total carcass sell price in thousand Korean won.

${ }^{1} \mathrm{SP}=$ Standardized partial regression coefficients as relative economic weight.

${ }^{2} \mathrm{TC}=$ Total path contribution that includes both direct and indirect effects. 


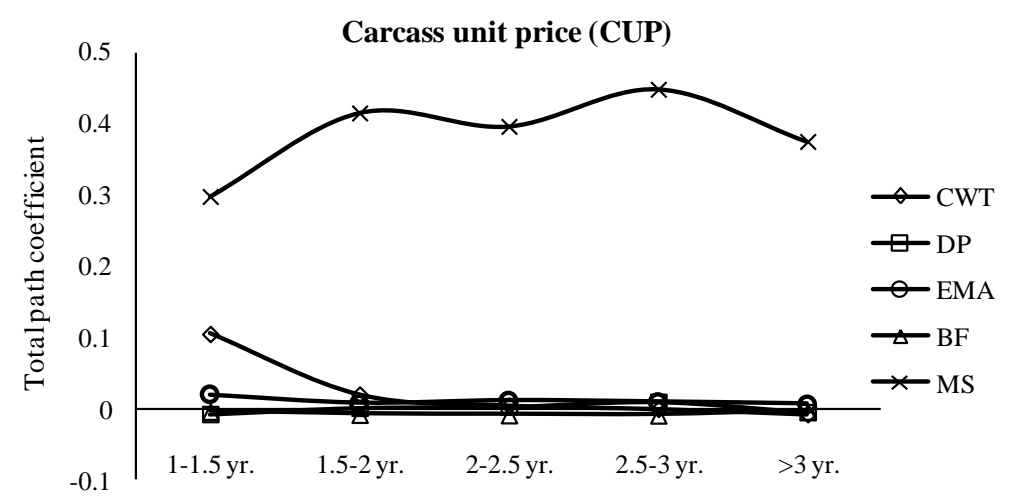

(A)

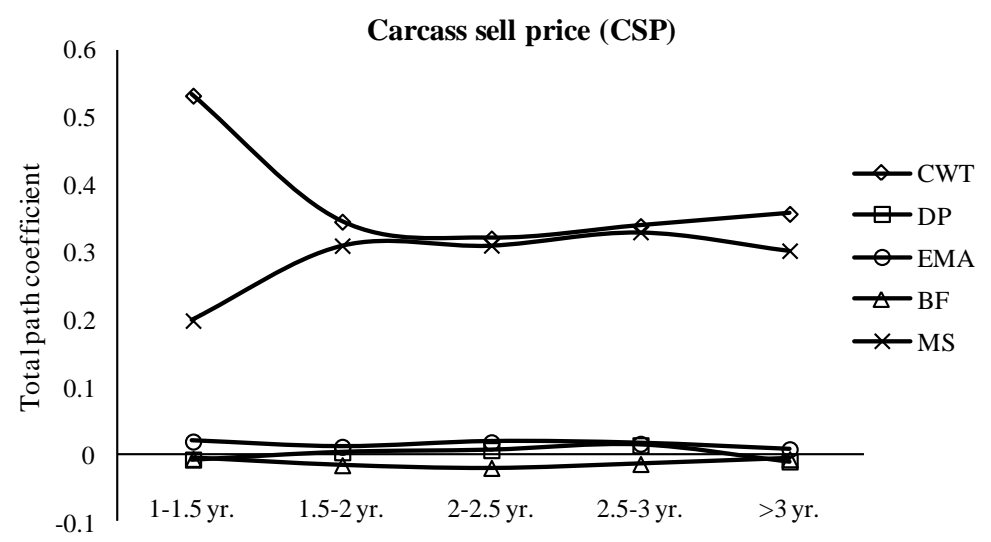

(B)

Figure 2. Path coefficients of carcass traits on (A) carcass unit price and (B) carcass sell price of Holstein steers according to age groups $(\mathrm{CWT}=$ Carcass weight; $\mathrm{DP}=$ Dressing percent; EMA $=$ Eye muscle area at 13th rib; $\mathrm{BF}=\mathrm{Backfat}$ thickness; $\mathrm{MS}=$ Marbling score).

CUP or CSP was obtained based on MS itself. On the contrary, the lower economic weights for EMA could reflect its lower influence on price settlement as in a dairy breed EMA is likely to be low.

Also, the varying relative economic weights of carcass traits at different age or time period as in Table 9, which is similar to Japanese cattle (Ibi et al., 2006), could indicate a high responsiveness of carcass prices based on market demands for carcass quality. Such a consequence might be based on consumer perceptions of meat quality rather than any particular preference invoked by animal feeders and, it seems to be supported by studies of Ibi et al. (2006) and Wilton and Goddard (1996). Furthermore, Holstein steers being a dairy breed are genetically leaner than beef breeds and thus, excessive BF is not a serious concern if Holstein is raised for longer period. This could again be predictable from the higher economic weights of MS given to older steers (Table 9) which indirectly depicts an acceptance of farmers of the need to feed animals for longer period to achieve better marbling in Holsteins. An opposite response is seen in beef breeds like Korean Hanwoo cattle (Kim et al., 2010a,b) or Japanese brown cattle (Ibi et al., 2006) where heavier carcasses are less accepted and feeding for a long time leads to excessive BF along with increased CWT and high MS which results a price cut due to over fatness.

The lower $\mathrm{R}^{2}$ of the regression models also signified that some variations in prices still remained unexplained from this study. Previously, Schultz and Marsh (1985) found that increased consumer's income also increased steer production whereas, a reduction in steers numbers were noticed when overall meat production increased. This means that consumer demand, meat production and income level are interrelated and complex in nature. So, our undefined variances could due to stochastic error terms related to changes in production costs, changes in demand driven by income level, cultural aspects, economic depression, or any random error while grading meat by personnel at the slaughter houses all of which are difficult to model in any study.

To summarize, it can be noted that this study has revealed the importance of carcass traits on carcass prices. Most carcass traits basically implied positive influences on Holstein carcass prices. Among them marbling score played the major role in carcass unit price determination as well as 


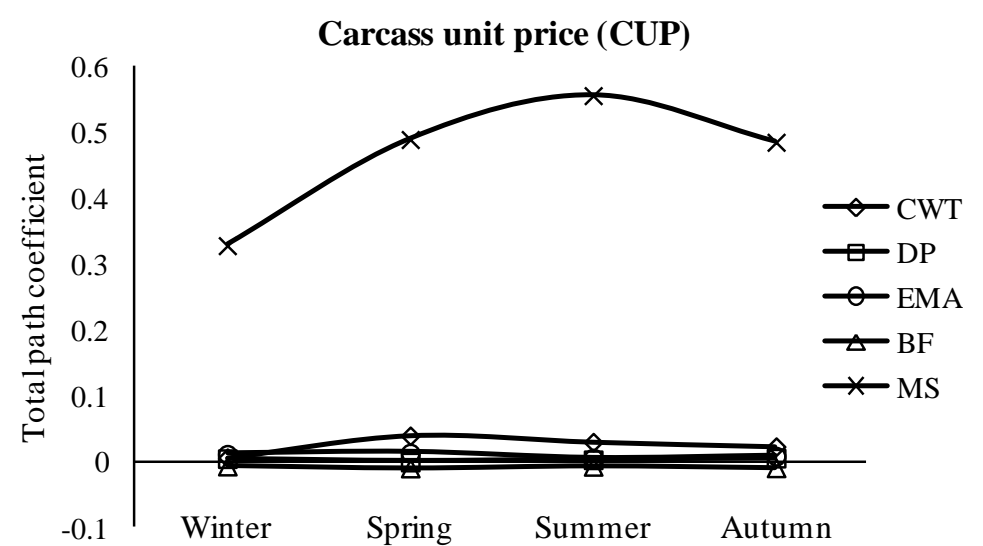

(A)

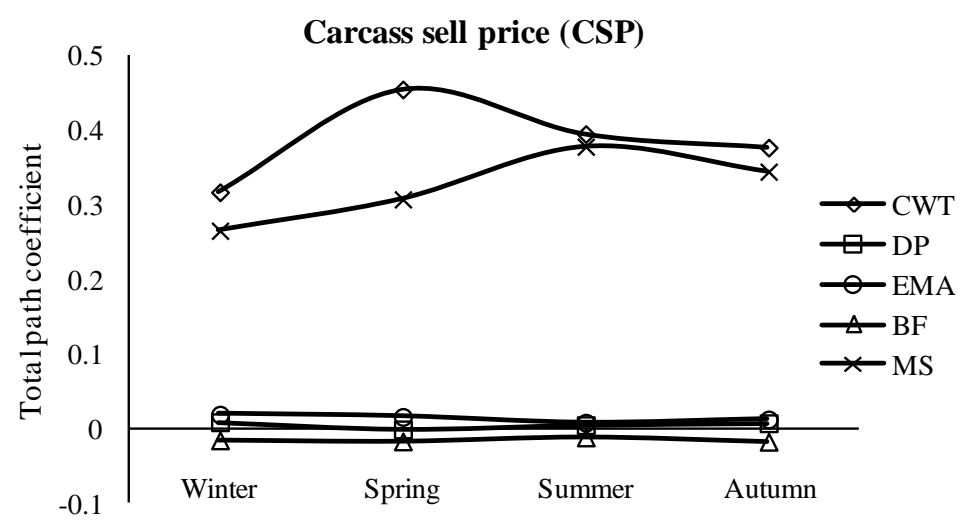

(B)

Figure 3. Path coefficients of carcass traits on (A) carcass unit price and (B) carcass sell price of Holstein steers according to season of slaughter $(\mathrm{CWT}=\mathrm{Carcass}$ weight; $\mathrm{DP}=$ Dressing percent; $\mathrm{EMA}=$ Eye muscle area at 13 th rib; $\mathrm{BF}=\mathrm{Backfat}$ thickness; MS = Marbling score) .

in total carcass sell price in conjunction with carcass weight. Especially, the carcasses with better marbling within 1.5 to 6 yrs received greater relative economic weights and heavier carcasses were ultimately allowed in the beef market. Also, a lesser economic weight in backfat thickness with its smaller total path contribution (effect) to overall carcass price variations ensured that $\mathrm{BF}$ had the minimal effect on income whereas, most of the profit was entitled to MS. Effects of season and age of slaughter on carcass price also provided a better realization about Holstein steer pricing. We hope that this knowledge of dairy steer carcass values will contribute in proper decision making regarding the production of Holsteins that respond to consumer demands in Korea alongside the local beef (Hanwoo) cattle.

\section{ACKNOWLEDGEMENT}

This research was supported by the RDA research grants (Project No. PJ907160, Development of economically important traits and technologies for sustainable dairy production).

\section{REFERENCES}

Abney, C. S. 2004. Feedlot performance, carcass and palatability traits, as well as subsequent economic relevance in calf-fed and yearling Holstein and Angus steers. M.S. Thesis, Michigan State University, Lansing, MI, USA.

Abraham, H. C., Z. L. Murphey, H. R. Cross, G. C. Smith, and W. J. Frank, Jr. 1980. Factors affecting beef carcass cutability: An evaluation of the USDA yield grades for beef. J. Anim. Sci. 50:841-851.

Baik, D. H., M. A. Hoque, G. H. Park, H. K. Park, K. S. Shim, and Y. H. Chung. 2003. Heritabilities and genetic correlation, and sire and environment effects on meat production potential of Hanwoo cattle. Asian-Aust. J. Anim. Sci. 16:1-5.

Bishop, G. L., T. E. Lawrence, and T. H. Montgomery. 2002. Predicting beef carcass value. Page 124 in Proc. Plains Nutr. Council Conf., TAMU Res. Ext. Center, Amarillo, TX. Publication No. AREC 02-20.

Cho, W. M., S. H. Yang, S. M. Lee, S. S. Jang, H. C. Kim, S. K. Hong, W. Y. Park, and H. S. Kim. 2012. Effects of different additives on the growth performance and carcass characteristics of Holstein steers. J. Life Sci. 22:61-166. (In Korean)

Dikeman, M. E., L. W. Cundiff, K. E. Gregory, K. E. Kemp, and R. 
M. Koch. 1998. Relative contributions of subcutaneous and intermuscular fat to yield and predictability of retail product, fat trim, and bone in beef carcasses. J. Anim. Sci. 76:16041612.

Galli, I., G. Teira, F. Perlo, P. Bonato, O. Tisocco, A. Monje, and S. Vittone. 2008. Animal performance and meat quality in cull cows with early weaned calves in Argentina. Meat Sci. 79:521528.

Garrett, W. N. 1971. Energetic efficiency of beef and dairy steers. J. Anim. Sci. 32:451-456.

Griffin, D. B. 1992. Excessive seam fat in primals and subprimals excess fat in beef trimmings. In: The final report of the national beef quality audit (Ed. G. C. Smith) 1991. Colorado State University, Fort Collins and Texas A \& M University, College Station.

Hwang, J. M., S. Kim, Y. H. Choy, H. B. Yoon, and C. J. Park. 2008. Genetic parameter estimation of carcass traits of Hanwoo steer. J. Anim. Sci. Technol. (Kor.). 50:613-620. (In Korean)

Ibi, T., A. K. Kahi, and H. Hirooka. 2006. Effect of carcass price fluctuations on genetic and economic evaluation of carcass traits in Japanese Black cattle. J. Anim. Sci. 84:3204-3211.

Jeremiah, L. E. 1996. The influence of subcutaneous fat thickness and marbling on beef: Palatability and consumer acceptability. Food Res. Int. 29:513-520.

Kahi, A. K., T. Oguni, Y. Sumio, and H. Hirooka. 2007. Genetic relationships between growth and carcass traits and profitability in Japanese Brown cattle. J. Anim. Sci. 85:348355.

Kauffman, R. G., M. E. Van Ess, R. A. Long, and D. M. Schaefer. 1975. Marbling: Its use in predicting beef carcass composition. J. Anim. Sci. 40:235-241.

Kim, D. G., K. K. Jung, S. K. sung, C. B. Choi, S. G. Kim, D. Y. Kim, and B. J. Choi. 1996. Effects of castration on the carcass characteristics of Hanwoo and Holstein. Korean J. Anim. Sci. (Kor.). 38:239-248. (In Korean)

Kim, J. B., D. J. Kim, J. K. Lee, and C.Y. Lee. 2010a. Genetic relationship between carcass traits and carcass price of Korean cattle. Asian-Aust. J. Anim. Sci. 23:848-854.

Kim, D. J., C. W. Lee, C. Y. Lee, and J. B. Kim. 2010b. Influence of carcass traits on carcass price in Mature Hanwoo cow. J. Anim. Sci. Technol. (Kor). 52:157-164. (In Korean)

Knapp, R. H., C. A. Terry, J. W. Savell, H. R. Cross, W. L. Mies, and J. W. Edwards. 1989. Characterization of cattle types to meet specific beef targets. J. Anim. Sci. 67:2294-2308.

Lawrence, J. D., Z. Wang, and D. Loy. 1999. Elements of cattle feeding profitability in Midwest feedlots. J. Agric. Appl. Econ. 31:349-357.

Lee, J. W., S. B. Choi, J. S. Kim, J. F. Keown, and L. D. Van Vleck. 2000. Parameter estimates for genetic effects on carcass traits of Korean Native Cattle. J. Anim. Sci. 78:1181-1190.

Lorenzen, C. L., D. S. Hale, D. B. Griffin, J. W. Savell, K. E. Belk, T. L. Frederick, M. F. Miller, T. H. Montgomery, and G. C. Smith. 1993. National beef quality audit: Survey of producerrelated defects and carcass quality and quantity attributes. J. Anim. Sci. 71:1495-1502.

Lunt, D. K., R. R. Riley, and S. B. Smith. 1993. Growth and Carcass Characteristics of Angus and American Wagyu steers. Meat Sci. 34:327-334.
Lynch, M. and B. Walsh. 1998. Genetics and analysis of quantitative traits. Sinauer Associates, Inc. Sunderland, MA.

Martin, R. J. and L. L. Wilson. 1974. Comparison of tissue enzyme levels and carcass characteristics in Hereford and Holstein steers. J. Anim. Sci. 39:865-870.

MAFRA (Ministry for Agriculture, Food and Rural Affairs). 2011. The Grading standards for livestock products. Official announcement 2011-171. (In Korean)

MFAFF (Ministry for Food, Agriculture, Forestry and Fisheries). 2008. The goals for animal improvement. Official announcement 2008-16. (In Korean)

Moon, S. S., I. H. Hwang, S. K. Jin, J. G. Lee, S. T. Joo, and G. B. Park. 2003. Carcass traits determining quality and yield grades of Hanwoo steers. Asian-Aust. J. Anim. Sci. 16:1049-1054.

Moon, W. G., B. W. Kim, S. H. Roh, H. S. Kim, D. J. Jung, D. W. Sun, K. N. Kim, Y. T. Yoon, J. H. Jung, J. T. Jeon, and J. G. Lee. 2007. Estimation of environmental effect and genetic parameters for the carcass traits in Hanwoo (Korean cattle). J. Anim. Sci. Technol. (Kor.). 49:689-698. (In Korean)

NLRI (National Livestock Research Institute). 2002. Annual Research Report. Rural Development Administration, South Korea, pp. 85-87.

Park, G. B., S. S. Moon, Y. D. Ko, J. K. H, H. H. Chang, and S. T. Joo. 2002. Influence of slaughter weight and sex on yield and quality grades of Hanwoo (Korean native cattle) carcasses. J. Anim. Sci. 80:129-136.

Pritchard, R. 1999. Changes which affect your profit. Available: http:// www.beeflinks.com/ProfitChanges.pdf. Accessed: Feb. $13,2013$.

Pyatt, N. A., L. L. Berger, D. B. Faulkner, P. M. Walker, and S. L. Rodriguez-Zas. 2005. Factors affecting carcass value and profitability in early-weaned Simmental steers: I. Five-year average pricing. J. Anim. Sci. 83:2918-2925.

Rios-Utrera, A., L. V. Cundiff, K. E. Gregory, R. M. Koch, M. E. Dikeman, M. Koohmaraie, and L. D. Van Vleck. 2005. Genetic analysis of carcass traits of steers adjusted to age, weight, or fat thickness slaughter endpoints. J. Anim. Sci. 83:764-776.

Schroeder, T. C., M. L. Albright, M. R. Langemeier, and J. R. Mintert. 1993. Factors affecting cattle feeding profitability. J. Am. Soc. Farm Mgrs. Rural Appraisers. 57:48-54.

Schultz, R. W. and J. M. Marsh. 1985. Steer and heifer price differences in the live cattle and carcass markets. Western J. Agric. Econ. 10:77-92.

Smith, T., J. D. Domingue, J. C. Paschal, D. E. Franke, T. D. Bidner, and G. Whipple. 2007. Genetic parameters for growth and carcass traits of Brahman steers. J. Anim. Sci. 85:13771384.

Wilton, J. W. and M. E. Goddard. 1996. Selection for carcass and feedlot traits considering alternative slaughter end points and optimized management. J. Anim. Sci. 74:37-45.

Yun. Y. T., D. G. Kim, and S. K. Sung. 1994. A study on the major carcass traits of the Hanwoo (Korean Native cattle) and Holstein by the various carcass weight classes. Korean J. Anim. Sci. 36(2):175-183. (In Korean)

Zaujec, K., J. Mojto, and M. Gondekova. 2009. Comparison of carcass quality of Slovak Pied and Holstein bulls by SEUROP system. Slovak J. Anim. Sci. 42:38-43. 